Pecvnia, 10 (2010), pp. 231-263

\title{
El empobrecimiento de los trabajadores como fuente de excedente en economías con débil dinámica productiva. Argentina desde mediados del siglo $\mathbf{X X}^{*}$
}

Recibido: Febrero 2010 Aceptado: Mayo 2010

\author{
Damián Kennedy \\ damian.kennedy@hotmail.com \\ Juan M. Graña \\ juan.m.grana@gmail.com \\ Universidad de Buenos Aires \\ Facultad de Ciencias Económicas \\ Av. Córdoba 2122 \\ Ciudad Autónoma de Buenos Aires (Argentina)
}

Este trabajo se propone analizar el desempeño de la economía argentina desde mediados del siglo XX, recurriendo al análisis de la distribución funcional del ingreso y sus componentes -salario real y la productividad-, tanto para la economía agregada como para el sector industrial.

A partir de la comparación con un conjunto de países desarrollados (Estados Unidos, Francia, Italia, Japón y España), encontramos que dichas
This paper analyses the performance of the Argentine economy since the 1950s, through the analysis of the functional distribution of income and its components -real wage and productivity- for the economy and especially the manufacturing sector.

Through comparisons with a group of developed countries (France, Italy, Japan and Spain, USA), we find that those variables have a

Este trabajo se realizó en el marco del Proyecto UBACyT E-021 "Recuperación y crecimiento económico: potencialidades y límites para el empleo y el bienestar en la Argentina", dirigido por Javier Lindenboim. Agradecemos los comentarios de Javier Lindenboim, Laura Pacífico, Pilar Piqué y Jimena Valdez. 
variables presentan desde mediados de la década del setenta una evolución particularmente llamativa: la productividad crece a un ritmo inferior -incluso con momentos de caída o estancamiento- y el salario real retrocede marcadamente.

En este marco, discutimos la explicación según la cual el empobrecimiento de los trabajadores argentinos es el resultado del proceso de desindustrialización sufrido -aunque sus indicadores se verifican con similar intensidad en aquellos países-, cambiando el eje hacia el débil desempeño de la productividad -y la consecuente ampliación de su brecha relativa-, que implica mayores costos para las empresas, que deben ser compensados con fuentes extraordinarias de ganancia. Una de ellas es, claro está, el salario real, de modo que el empobrecimiento de los trabajadores en Argentina resulta una pieza necesaria en el marco de la forma que adopta el proceso económico.

Palabras clave: Distribución funcional del ingreso, Productividad, Salario real, Industria. striking evolution: the productivity grows at an inferior rate -including periods of stagnationand the real wage falls dramatically.

We then challenge the existing explanation of the impoverishment of the Argentine working class: the decline of our manufacturing sector. Since Argentinean indicators are no different than those of other countries, we emphasize the weak performance of the productivity -and the growth of the relative gap- that means higher costs for the firms, that must be compensated with extraordinary sources of profit. One of them is the real wage, and therefore the impoverishment of Argentine workers is a necessary piece of the economic process.

Key words: Factorial income distribution, Productivity, Real wage, Manufacturing.

\section{INTRODUCCIÓN}

A pesar de la importancia que la distribución funcional o factorial del ingreso ${ }^{1}$ tiene para las más diversas corrientes teóricas, y del rol fundamental que ocupó en la investigación y el debate económico de Argentina en determinados momentos históricos, su análisis ha sido abandonado progresivamente desde mediados de los setenta, para prácticamente desaparecer hacia la década del noventa, en el contexto de una creciente ausencia de información oficial (y no oficial) al respecto. Afortunadamente, en los últimos años comenzaron a revertirse tímidamente dichas tendencias, tanto respecto al estudio como a la información. En este marco se inscribe nuestra investigación en torno a la participación asalariada en el ingreso, que se inició hace aproximadamente un lustro con la estimación de la serie (por entonces inexistente) para el lapso 1993-2004 (Lindenboim et al. 2005), y que ha estudiado distintos aspectos

1 Esto es, la porción del producto total que se apropian los trabajadores mediante sus remuneraciones y los empresarios en las diferentes formas de excedente. 
parciales de la misma, que creemos relevantes para la comprensión del proceso económico de un país, en nuestro caso la Argentina.

Más específicamente, la focalización de la mirada en la apropiación de la nueva riqueza generada en el país en cada año permite, por un lado, revelar la forma en la cual se utiliza la fuerza de trabajo, a partir del análisis de la relación entre el salario real y la productividad. Por el otro, el contraponer la faceta del ingreso de la nueva riqueza producida a la de la demanda final, permite reconocer la forma en la cual se realizan los bienes finales producidos por la economía; en otros términos, establece la relación, por un lado, entre masa salarial y consumo y, por el otro, entre excedente económico e inversión. Así, en Lindenboim et al. (2010) hemos intentado plasmar un análisis conjunto de ambos aspectos para la Argentina desde mediados del siglo XX hasta la actualidad ${ }^{2}$, a la vez que en Kennedy y Graña (2009) desarrollamos el primer aspecto específicamente para el sector industrial. Como conclusión más importante, encontramos que el profundo deterioro de la participación asalariada sucedido en nuestro país desde mediados de la década del setenta se explica no sólo por incrementos de productividad no transferidos a salarios, sino también por un auténtico derrumbe del salario real, que hacia 2006 tiene un nivel aproximadamente $30 \%$ inferior al de inicios de los años setenta.

En este contexto, el presente artículo se propone poner en perspectiva internacional las tendencias observadas en la economía argentina en lo que respecta a la participación asalariada del ingreso y sus componentes -productividad y salario real- tanto para la economía agregada como para la industria, a lo largo de los últimos cincuenta años. El objetivo fundamental es avanzar en la comprensión de las razones que se encuentran detrás del débil comportamiento de la economía nacional en general, y del profundo deterioro sufrido por la clase trabajadora en particular, poniendo en cuestión la explicación más difundida en nuestro país, según la cual tales procesos se deben exclusivamente al proceso de desindustrialización iniciado con el golpe militar de 1976 y profundizado en la década de los noventa.

Los países que utilizaremos para la comparación son Estados Unidos, Francia, Italia, Japón y España, a partir de la información de Cuentas

2 En rigor, el período de análisis se extiende hasta 2006, habida cuenta la intervención y la manipulación de la información a la que fue sometido el Instituto Nacional de Estadísticas y Censos (INDEC) de Argentina, que se tradujo, según el tipo de indicador, en la inaccesibilidad o manipulación de los procedimientos de elaboración de los mismos. 
Nacionales provista por los respectivos institutos nacionales de estadísticas. Una razón por la que los mismos fueron elegidos es la facilidad de obtener las series cuantitativas necesarias para el período de referencia, que no son habitualmente encontradas en países como el nuestro. Pero existe una razón de mayor importancia: la de contrastar las tendencias observadas en nuestro país con las vigentes en países que, al menos según habitualmente se cree, han alcanzado un mayor grado de desarrollo capitalista. Evidentemente, en ninguno de los dos aspectos la lista de países en cuestión es exhaustiva; ahora bien, creemos que a los fines del presente trabajo la misma resulta suficiente.

Para tal fin, en la primera sección repasamos la evolución de la participación asalariada en el ingreso en Argentina desde mediados del siglo pasado hasta la actualidad, comparándola con la evidenciada por los países seleccionados. En la segunda sección presentamos, en primer lugar, el desarrollo conceptual que nos conduce a identificar a la productividad y el salario real como las variables determinantes de la participación asalariada, para luego analizar su evolución para nuestro país en perspectiva internacional, siempre para la economía en su conjunto. Por su parte, en la tercera sección hacemos lo propio exclusivamente para el sector industrial. En la cuarta sección evaluamos en qué medida el devenir económico de nuestro país desde mediados de los años setenta se caracteriza por un proceso de desindustrialización. Finalmente, en la quinta sección procuramos, a partir de una mirada de conjunto de los resultados alcanzados a lo largo del trabajo, presentar y proponer algunas líneas de análisis que contribuyan al debate en torno a las características del proceso económico en Argentina.

2. EL PUNTO DE PARTIDA: MEDIO SIGLO DE DISTRIBUCIÓN FUNCIONAL DEL INGRESO EN ARGENTINA EN PERSPECTIVA INTERNACIONAL

Con diferentes percepciones en torno del mismo, se encuentra una plena coincidencia en la literatura sobre que en Argentina, a tono con la experiencia de otras economías latinoamericanas, rigió hasta mediados de los años setenta el modelo de industrialización por sustitución de importaciones (ISI), basado en el incentivo a la industria nacional a través de la protección externa y el fomento del mercado 
interno ${ }^{3}$, el cual se vio interrumpido abruptamente por el golpe militar que se extendió entre 1976 y 1983. Si bien es un debate aún abierto si el referido modelo estaba o no en sí mismo agotado, así como también cuál es la lógica de funcionamiento del instaurado en su reemplazo, existe un acuerdo relativamente generalizado de sus características fundamentales, principalmente durante el gobierno militar y el régimen de la Convertibilidad (1991-2001): apertura comercial y financiera, endeudamiento externo, sobrevaluación de la moneda, desindustrialización, reprimarización e incremento de la inversión en los sectores financieros. Sobre esta base, se sugirieron denominaciones tales como "apertura con endeudamiento externo" o de "valorización financiera" (Damill y Frenkel 1993; Ferrer 2004; Basualdo 2006 y Schvarzer y Tavosnaska 2008).

Como queda expresado en el Gráfico 1, la participación de los asalariados en el ingreso total muestra evoluciones muy diferentes entre el período de la ISI y las últimas tres décadas. Así, desde el comienzo del período y hasta 1955 (año del derrocamiento del segundo gobierno peronista), la participación se encuentra entre el 45 y el $50 \%$ del ingreso total, momento a partir del cual experimenta un gran retroceso, para llegar en 1959 al 36,5\%. Luego de la inestabilidad de principios de los sesenta, y en el marco del proceso conocido como "segunda ISI"4, comienza una sostenida recuperación, tal que la participación se ubica, hacia inicios de los setenta, entre el 42,5 y el $45 \%$, esto es, un escalón debajo del nivel de la década previa.

La nueva (e importante) recuperación de los años 19721974 (este último año es uno de los dos, junto con 1954, máximos de la serie) es el preludio de, primero, la caída de 1,5 puntos porcentuales (pp) consecuencia del plan de ajuste de $1975^{5}$, y luego, de su derrumbe de 17pp, resultado de la irrupción de la dictadura militar en 1976. Si sumamos

3 Aunque nuestro período de análisis comienza en 1950, cabe señalar que los primeros indicios de la ISI en Argentina se dan a partir de los efectos de la "crisis del treinta" (cuando se comienzan a poner en funciones las instituciones que darían lugar a ese proceso, entre las que se destacan las Juntas Reguladoras de las diferentes producciones agrícolas así como la elevación de los impuestos a la importación), cobrando un nuevo impulso en el marco de la Segunda Guerra Mundial.

4 En él se procuró avanzar más allá de la promoción de la industria liviana a través de la implantación de empresas multinacionales en la producción de bienes de consumo durables -principalmente automóviles- y de insumos básicos. Esa estrategia es conocida como "desarrollismo" y fue impulsada inicialmente, pero no exclusivamente, por el gobierno de Frondizi (1958-1962).

5 Conocido como "Rodrigazo", en referencia al apellido del Ministro de Economía que lo impulsó: Celestino Rodrigo. 
la nueva retracción de 1977, la participación cae por debajo del 30\%, 7pp por debajo de su -hasta entonces- mínimo histórico de 1959.

Gráfico 1: Participación salarial en el PBI a costo de factores o precios básicos. Total de la economía. Argentina, España, EE.UU., Francia, Italia y Japón. 1950-2008. En porcentaje

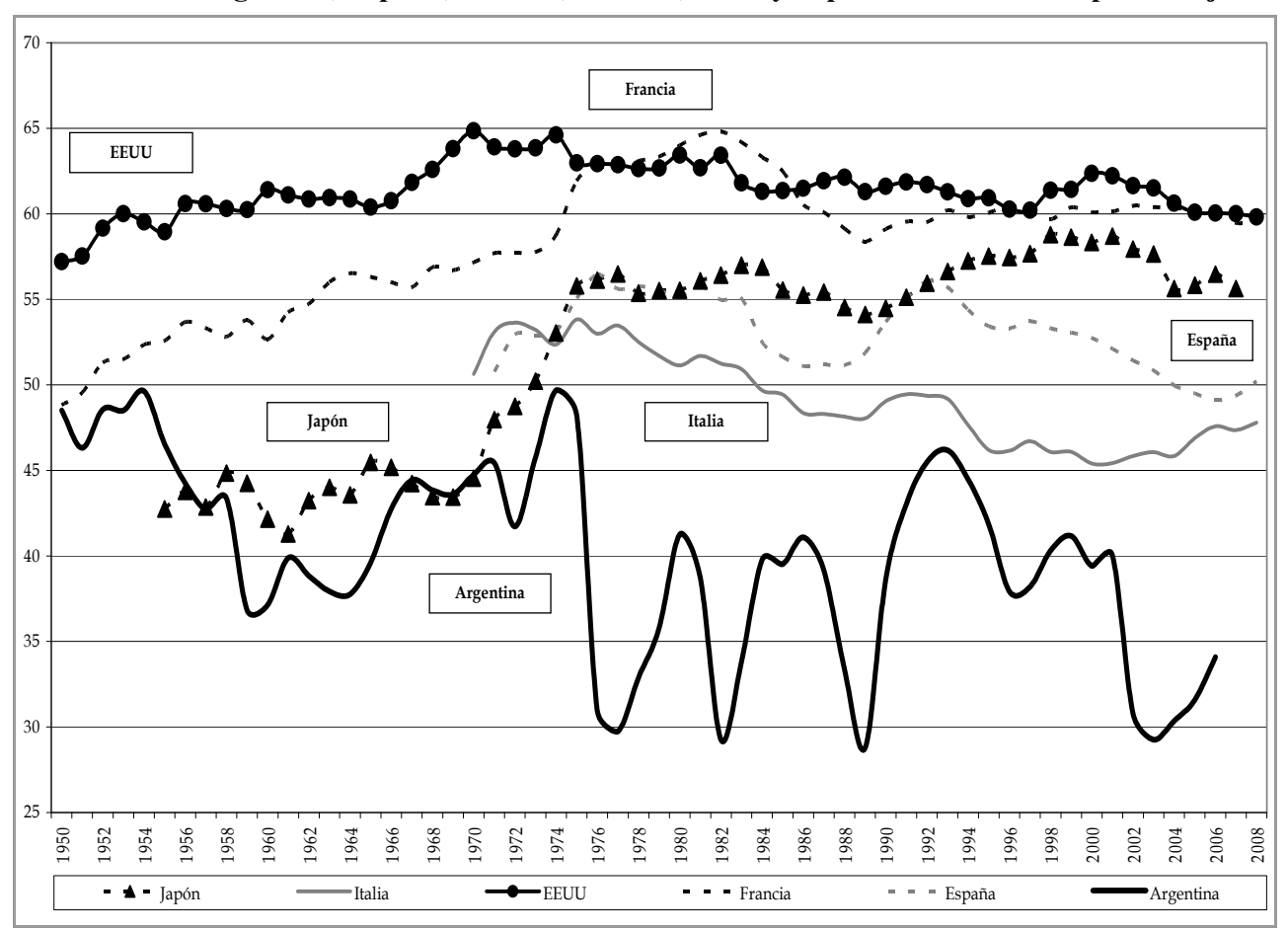

Fuente: Graña y Kennedy (2008b) y elaboración propia sobre la base de Instituto Nacional de Estadística (INE España), Bureau of Economic Analysis (BEA - EE.UU.), Institut National de la Statistique et des Études Économiques (INSEE - Francia), Istituto Nazionale di Statistica (ISTAT - Italia) y Statistics Bureau of Japan.

A partir de allí, la participación asalariada ingresa en un período de fuertes oscilaciones entre dicho mínimo y el $40 \%$ del producto. Así, el crecimiento hasta 1980 se desmorona en los últimos años del gobierno de facto, tal que en 1982 presenta un nivel cercano al 29\%, proporción aún menor que el mínimo alcanzado en 1977. Por su parte, la recuperación observada con la vuelta de la democracia en 1983 y su mantenimiento entre 1984 y 1986 vuelve a perderse por completo hacia finales del gobierno de Alfonsín, llegando en 1989, proceso hiperinflacionario de por medio, a un nuevo mínimo histórico (28,6\%). Hacia inicios de los noventa la participación parece superar el "techo" vigente durante tantos años, al alcanzar el 45,6\%, aunque con la "crisis del tequila" a mediados de la década retrocede hasta el 37,4, para luego derrumbarse 12pp con la gran devaluación de 2002 
que marcó el final de la Convertibilidad, ubicándose nuevamente en el mínimo histórico.

En resumidas cuentas, la irrupción de la dictadura militar implicó un brutal descenso de la participación asalariada, llevándola a un mínimo en torno al $30 \%$ del ingreso total, nivel al cual volvió recurrentemente como consecuencia de la crisis de la deuda externa (1982), la hiperinflación (1989-1990) y el fin de la Convertibilidad (2002). El crecimiento de los años recientes, aunque importante, no logró recuperar lo perdido con la devaluación de 2002.

En el mismo Gráfico 1 presentamos también la participación asalariada para el grupo de países seleccionados. Sin pretender abarcar en profundidad todas estas evoluciones ni todos los períodos históricos, lo que inmediatamente salta a la vista es que la dinámica de la misma en nuestro país comparte con la de aquellos la tendencia decreciente desde mediados de los años setenta ${ }^{6}$, pero contrasta abiertamente en lo que respecta tanto a la magnitud como a la variabilidad de dicha caída. Así, mientras que en términos generales la participación asalariada retrocede alrededor de $5 \mathrm{pp}$ en los últimos treinta años, en nuestro país, considerando no el "pico" de 1974 sino el nivel vigente a inicios de los setenta, la caída duplica esa cuantía. Por su parte, aunque con ciertos vaivenes, el retroceso de la participación en tales países es relativamente continuo, frente a los bruscos movimientos ya reseñados para el caso argentino.

Hasta aquí no hemos dicho nada acerca del nivel absoluto de la participación. Como se observa en el gráfico, existe una profunda brecha entre el correspondiente a nuestro país y el resto, obviamente ampliada desde mediados de los setenta, y más allá de que entre los países en cuestión también se verifican importantes diferencias. Ahora bien, aunque no descartamos la importancia de esta marcada diferencia para ciertas investigaciones, en lo que respecta al presente trabajo el foco de interés está puesto, como quedará aún más claro en lo que sigue, en la evolución de las distintas variables analizadas, y no tanto en su valor absoluto.

En este sentido, ¿qué hay detrás de estos números? ¿De qué depende la evolución de la distribución funcional del ingreso? ¿Cómo se explica semejante deterioro y variabilidad de la participación asalariada en nuestro país, a diferencia de lo observado en el resto de los países

6 A excepción del comportamiento japonés que, en esa década, acelera su crecimiento y mantiene tal nivel hasta la actualidad. 
analizados? Esta cuestión es la que pretendemos abordar en la siguiente sección.

\section{ACERCA DEL CONTENIDO DE LA DISTRIBUCIÓN FUNCIONAL: LA EVOLUCIÓN DE LA PRODUCTIVIDAD Y EL SALARIO REAL}

funcional $^{7}$

\subsection{Identificación de los determinantes de la distribución}

Como en toda forma social de producción, en el capitalismo la sociedad debe resolver el problema de asignar su capacidad total de trabajo a sus diversas formas concretas. En tanto en este sistema el trabajo se realiza de manera privada, la relación de producción no se manifiesta como directamente social, sino que se presenta como la posibilidad de cambiar los productos del trabajo. Como tales, éstos expresan lo que sus productores no pueden poner de manifiesto directamente: el ser (potencialmente) una porción determinada del trabajo social total. En este sentido, los productos del trabajo asumen el carácter de valor.

Desde el punto de vista social, este trabajo materializado no interesa en tanto trabajo concreto productor de valores de uso, sino como trabajo en sentido general, como trabajo abstracto. En relación a su cantidad, en el mismo sentido, no interesa cuánto tiempo gastó cada productor particular, sino el tiempo socialmente necesario para su producción ${ }^{8}$. A su vez, dado el carácter privado del trabajo, cada producto del trabajo no puede expresar directamente su valor no teniendo más forma de hacerlo que en su relación con el resto de las mercancías. La forma bajo la cual todas las mercancías expresan al mismo tiempo su valor es el precio, esto es, en una mercancía particular que asume el carácter de equivalente general o dinero9. Así, la nueva riqueza social

\footnotetext{
El contenido de este apartado es una síntesis de lo presentado en Graña y Kennedy (2008a), donde también desarrollamos la "desagregación matemática de la distribución funcional del ingreso", que conduce a idéntico resultado.

8 Nótese que no se trata de un simple promedio entre los distintos productores, sino del tiempo de trabajo que se corresponde con las condiciones medias de producción imperantes en cada rama.

9 En abstracto, cualquier mercancía podría ocupar tal lugar, pues todas son expresiones de trabajo humano abstracto. Sin embargo, la mercancía que ocupa esa posición es aquella que, en función de sus propiedades materiales para tal fin y por fuerza de la costumbre social, se impone como tal. En general, ese lugar ha sido asignado al oro, convirtiéndose así en la mercancía dineraria o dinero. A su vez, dadas sus funciones en la circulación, la mercancía dineraria puede ser reemplazada por signos de valor.
} 
producida en un determinado período (que se expresa, alternativamente, como el conjunto de mercancías finales producidas o como el ingreso generado) tiene la forma específica de masa de valor.

Dado el objetivo genérico de toda organización social de que la masa de riqueza social resultante debe ser mayor que la utilizada para su creación (esto es, que el trabajo encerrado en el resultado de un ciclo productivo exceda al que costó su producción), en el capitalismo esto implica que aquella masa de valor encierra un excedente. Éste brota de la diferencia entre el trabajo que cuesta producir a la fuerza de trabajo en tanto mercancía y el que ésta despliega en la jornada de trabajo; en otros términos, surge del hecho de que el valor de la fuerza de trabajo representado en el salario es menor al valor creado por los trabajadores. De esta forma, la distribución funcional del ingreso constituye la expresión monetaria de la distribución del valor total creado por los asalariados entre lo que ellos perciben como salario (es decir, la masa salarial) y el excedente.

Pero esto no es todo; la necesidad de incrementar la capacidad productiva del trabajo (esto es, la potencialidad de la apropiación humana del medio) implica que dicho excedente debe ser, a su vez, creciente. La forma concreta que adopta este proceso es a través de la "maximización de los beneficios" de la empresa. Para ello, en términos generales, desarrolla mejoras productivas con el objetivo de reducir los costos individuales y obtener una ganancia extraordinaria; al generalizarse aquéllas e incrementarse "verdaderamente" la productividad, disminuye el valor de la mercancía. Si, de un lado, lo anterior determina la desaparición de la ganancia extraordinaria, del otro (siempre que corresponda a ramas que producen bienes de consumo asalariado directa o indirectamente) implica una reducción del valor de la fuerza de trabajo $y$, manteniendo el poder adquisitivo del salario, un incremento (relativo y absoluto) del excedente. Aunque este es su contenido general, en tanto tal incremento productivo requiere -término medio y en el largo plazouna creciente calificación del conjunto de trabajadores, el salario real de éstos debe aumentar al crecer el valor que porta su fuerza de trabajo. Es de esperar, entonces, que una mayor productividad vaya acompañada de incrementos salariales; es decir, no todo crecimiento de aquella debe traducirse únicamente en ganancia.

Como consecuencia de lo anterior, la tendencia de la participación asalariada en el ingreso está determinada por la relación entre la evolución del rendimiento de los trabajadores (productividad) y 
la remuneración real por éstos percibida, teniendo con esta última una relación directa y con la primera una inversa ${ }^{10}$.

\subsection{La situación de Argentina desde mediados del siglo XX}

En el Gráfico 2 expresamos la evolución de la participación asalariada en el ingreso, el salario real y la productividad para la Argentina a lo largo del período en cuestión ${ }^{11}$. A los fines de la comparación internacional que se desarrollará a continuación, tomamos como punto de comparación el promedio de los tres años comprendidos entre 1970 y $1972^{12}$.

En relación a la productividad, puede verse que los primeros veinte años de la serie constituyen un período de clara expansión -con algunos años de estancamiento-, incrementándose en conjunto un $64 \%$. Este comportamiento de crecimiento estable y continuo vigente bajo la ISI se verá profundamente modificado a partir de mediados de los años

10 La relación entre ambas variables ha sido analizada en nuestro país por otros autores (Féliz y Pérez 2004 y González 2007). En este marco, el rasgo distintivo de nuestro enfoque es identificar el modo en que esa relación determina la evolución de la distribución funcional del ingreso. Al respecto, es importante señalar que en la relación que cada una de estas variables tiene con la participación asalariada en el ingreso juega un papel importante la cuestión del trabajo improductivo. En tanto el salario de aquellos que realizan trabajo improductivo tiene como fuente el excedente producido por el trabajo productivo, un incremento del trabajo improductivo en el total del trabajo social implicaría un incremento per se la participación asalariada. El debate aún no resuelto en la literatura respecto de qué es (y qué no) trabajo improductivo, y aún más, cómo identificarlo en la práctica a los fines de medir sus efectos, hacen que dejemos de lado esta cuestión a los fines de este artículo.

11 La metodología de estimación de estas variables para la Argentina se encuentra desarrollada en Graña y Kennedy (2008b), la cual reproducimos aquí para los países seleccionados, tanto a nivel agregado como para el sector industrial. De manera muy concisa, el punto de partida son las estimaciones del Sistema de Cuentas Nacionales para los agregados de remuneración al trabajo asalariado (que incluye los aportes y contribuciones al sistema de seguridad social), el producto a precios corrientes y a precios constantes (total o sectorial dependiendo del caso), y el número absoluto de ocupados y asalariados. A partir del cociente entre la remuneración al trabajo y el total de asalariados se obtiene un salario medio doble bruto, el cual luego se deflacta con el Índice de Precios al Consumidor para obtener el salario real. Por su parte, a partir del cociente entre el producto a precios constantes (indicador de la producción material) y el total de ocupados, surge la estimación de la productividad, también denominada producto medio o producto por trabajador. La comparabilidad internacional de los datos, aunque puede no ser perfecta, se encuentra avalada por las normas del Sistema de Cuentas Nacionales en sus diferentes bases.

12 Aunque habitualmente consideramos como año de referencia el año 1970, al no disponer de la información de las variables aquí implicadas para España para ese año, optamos por tomar dicho promedio como referencia, de modo que el punto de comparación sea, para el caso del total de la economía, el mismo para todos los países. Por otro lado, es importante destacar que aunque para reflejar el punto de inflexión de la historia de nuestro país pareciera ser apropiado tomar como punto de referencia el año 1974, optamos por no considerarlo como tal, habida cuenta del relativo cuestionamiento que existe en torno a la calidad de las estadísticas de este año. En cualquier caso, considerar dicho año, en tanto es máximo histórico del nivel de participación asalariada y del salario real, mostraría un panorama aún más sombrío para nuestro país. 
setenta. Así, entre el golpe militar de 1976 y la implantación del régimen de Convertibilidad en 1991 la productividad muestra un estancamiento durante la vigencia del gobierno militar y un retroceso en el resto de la de la década del ochenta ${ }^{13}$, en ambos casos con un comportamiento particularmente oscilante. Así, la productividad de 1990 fue un 6\% inferior a la del promedio 1970-1972. Es decir, en casi 20 años la capacidad productiva promedio del trabajo en Argentina no avanzó ni un ápice.

La situación parece revertirse completamente en "los noventa", particularmente en los primeros años de la década, expandiéndose más de un $25 \%$ entre 1990 y 1994. Ahora bien, en este punto es muy importante destacar lo siguiente: este favorable comportamiento de la productividad se debe más a una destrucción de las empresas de menor productividad en el marco de la apertura comercial y la apreciación cambiaria (a lo que deben sumarse las privatizaciones de los servicios públicos) que a un genuino desarrollo de la capacidad productiva del trabajo ${ }^{14}$. Luego del estancamiento en el marco de la crisis del tequila, continúa el crecimiento de la productividad, el cual se verá completamente revertido por la recesión económica de los últimos años de la Convertibilidad (1998-2001).

En lo que hace al proceso actual, el incremento del producto (a tasas "chinas") se realizó sobre la base de una creciente absorción de fuerza de trabajo, de modo que la productividad no mostró un gran dinamismo, terminando apenas por encima del máximo de la Convertibilidad. De esta forma, podemos ver que hacia 2006 el nivel de la productividad es un $32 \%$ más alto que el vigente en el lapso de comparación.

En lo que respecta al salario real bajo la ISI, podemos observar que, en términos generales, presenta una tendencia positiva (a pesar de que el retroceso verificado entre 1958 y 1959 anula el incremento que, con oscilaciones, se había logrado a lo largo de la década), de modo que a principios de los setenta presenta un crecimiento, respecto de 1950 , de un $25 \%$. Los tres años siguientes repiten el crecimiento del cuarto de siglo anterior, aunque la situación es meramente pasajera: el "Rodrigazo" $y$, particularmente, la sangrienta dictadura militar, se llevan consigo no

13 Durante los años ochenta no se verifica ni siquiera un incremento del producto, lo que le valió a los años ochenta el mote de "década perdida".

14 Un claro reflejo de este proceso fue la evolución de la tasa de desempleo, que de niveles en torno al $6 \%$ de la población económicamente activa en los años ochenta trepó al $18 \%$ hacia mediados de los noventa. 
sólo ésta última expansión sino prácticamente la totalidad de lo avanzado desde mediados de siglo. A idéntico nivel se retorna en el fin de la dictadura, luego del crecimiento experimentado como resultado de la creciente apreciación cambiaria.

El crecimiento del $50 \%$ en los dos primeros años de la recuperación democrática resulta nuevamente efímero: los brotes inflacionarios de mediados de los ochenta y la hiperinflación final fueron más allá que la dictadura, tanto que el salario real de 1989 representaba apenas el 64\% del poder adquisitivo del promedio de 1970-1972. Aunque con un contexto marcadamente distinto, la lógica no fue muy diferente bajo la Convertibilidad: la estabilización nominal y la apreciación del peso logran inicialmente una recuperación del $35 \%$, en buena parte luego perdida por la desocupación, la precarización laboral y el estancamiento económico posterior.

Gráfico 2: Participación salarial en el PBI pb, productividad y salario real. Total de la economía. Argentina. 1950-2006. Evolución. Promedio 1970-1972 = 100

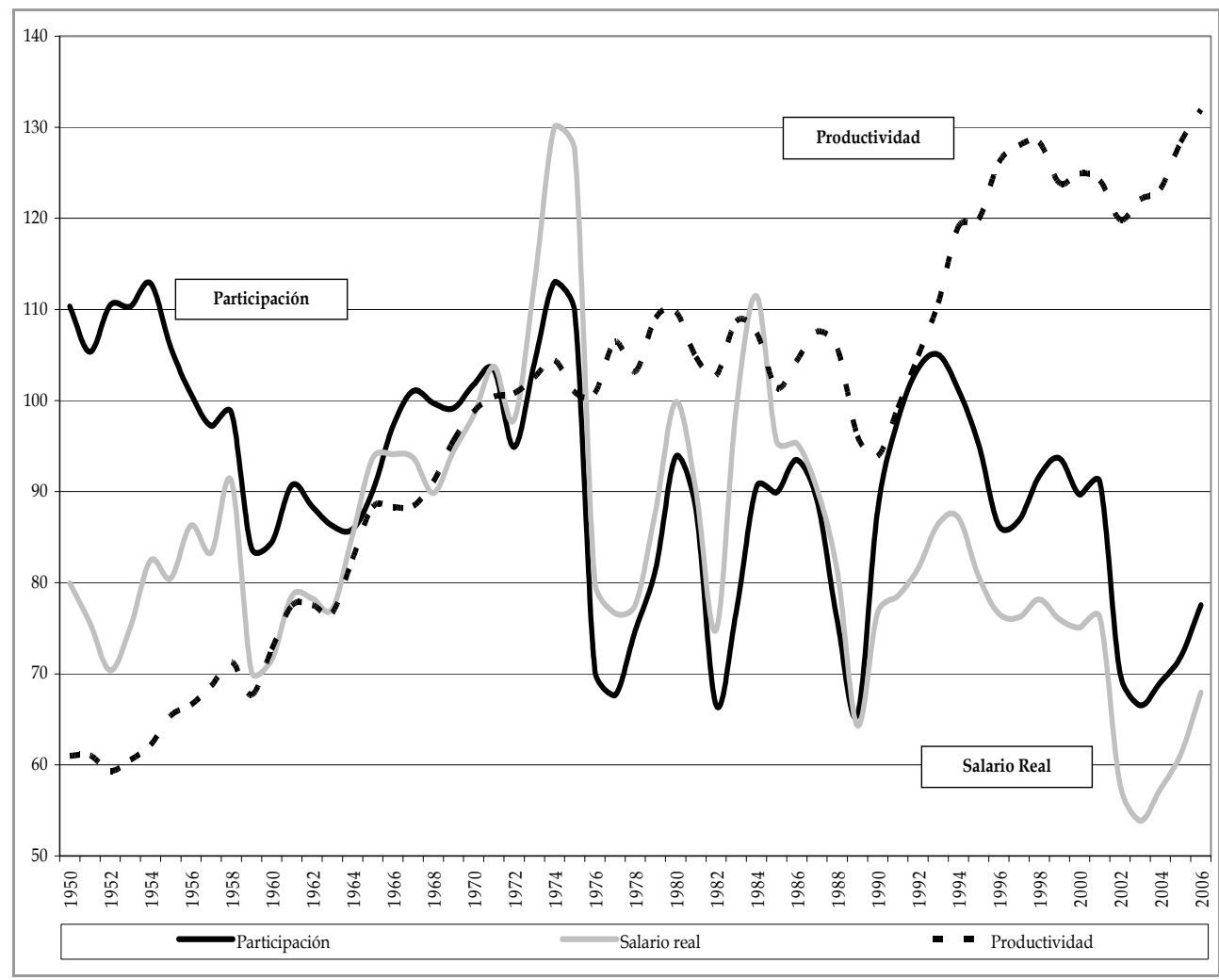

Fuente: Graña y Kennedy (2008b) 
Si se pensaba que ya no había lugar para el retroceso del poder adquisitivo del salario, la devaluación de enero de 2002, inflación mediante, viene a desmentirlo: las remuneraciones reales se derrumbaron más de 22pp entre 2001 y 2003, marcando un nuevo mínimo histórico, en tanto llegó a representar apenas algo más que la mitad que su nivel vigente en el promedio de 1970-1972. En los años recientes, a pesar del crecimiento del 26\%, el salario real no llegó en 2006 a recuperar la caída de la devaluación, de modo que en la actualidad la capacidad de consumo de los asalariados representa apenas un $69 \%$ de su nivel en los años de referencia ${ }^{15}$. 0 sea, en el último medio siglo la clase obrera argentina no ha podido avanzar ni un paso en su "calidad de vida", a la vez que en los últimos treinta años sólo la vio retroceder.

Veamos cómo la evolución de estas variables incidió en la dinámica de la distribución funcional del ingreso. Exceptuando los dos primeros años de la serie (donde el salario real evoluciona por encima de una productividad constante), hasta inicios de 1970 parece verse, en términos generales, un comportamiento como el esperado en la lógica de la producción capitalista: un retroceso de la participación asalariada en el ingreso causado por un incremento relativamente continuo de la productividad superior al del salario real $(64 \% \text { contra } 25 \%)^{16}$.

A partir de aquí y hasta comienzos de la década del noventa, la evolución de la participación se explica prácticamente por el movimiento del salario real, al estar la productividad relativamente constante 0 , incluso más, con una leve tendencia decreciente. Así, el aumento de la participación asalariada que ocurre hacia mediados de los setenta tiene que ver con un crecimiento del salario real por encima del de la productividad, situación completamente revertida por la dictadura, bajo la cual el deterioro del salario real (25\% en relación al promedio 1970-1972) explica el de la participación asalariada, aún con una productividad en disminución. Bajo el gobierno alfonsinista, no sólo la participación asalariada se mantuvo entre puntas- en su mínimo histórico, sino que detrás de la misma está el

15 Teniendo en cuenta conjuntamente el Índice de Precios al Consumidor elaborado por algunos organismos de estadísticas provinciales de la Argentina, en principio no manipulados, y los incrementos salariales nominales pactados en las diversas negociaciones entre sindicatos y patrones, el salario real en 2007 y 2008 como mucho mantuvo ese nivel.

16 Este proceso general puede dividirse en dos grandes subperíodos, donde el punto de quiebre se encuentra en los primeros años de los sesenta. Así, hasta tal momento el retroceso de la participación asalariada se explica por un incremento de productividad mayor al del salario real, mientras que el aumento del segundo subperíodo tiene que ver con un salario real algo más dinámico que la productividad. 
peor escenario posible: reducción del salario real (35\% entre 1983 y 1989) y de la productividad (12,7\% para el mismo período).

Entre 1989 y 2002 (es decir, a lo largo de la Convertibilidad y su salida) la participación asalariada también se mantiene en torno a ese mismo mínimo, caída en donde confluyen tanto una continuidad en el deterioro del salario real (10\%, exclusivamente atribuible a la devaluación), como así también un incremento de productividad (24\% en idéntico período). Finalmente, detrás de la recuperación de la participación asalariada actual encontramos un crecimiento del salario real mayor que el de la productividad (12,2 y 10,3\%, respectivamente), con una particularidad: mientras que ésta ya superó la pérdida post devaluación, aquél se encuentra un $8,5 \%$ por debajo de 2001 . Es por ello que el crecimiento de la participación del último tramo no compensa el derrumbe del fin de la paridad cambiaria, tanto que comparando con su nivel de 2001 la razón del deterioro se encuentra pura y exclusivamente en la reducción de las remuneraciones reales.

En síntesis, mirando el proceso 1950-2006, la conclusión es evidente: el deterioro de la participación asalariada, que pasa del 48 al $34 \%$ del ingreso total, expresa un incremento de la productividad del $116 \%$ conjuntamente con un deterioro del salario real del $15 \%$. Este proceso de casi sesenta años posee varios subperíodos de importancia, pero sin duda el principal punto de inflexión se encuentra a mediados de los setenta. En ambos, considerados entre puntas, la participación asalariada retrocede, aunque por razones completamente diferentes. Como vimos, en la ISI el crecimiento del $64 \%$ de la productividad viene en paralelo a uno del salario real del 25\% (la participación asalariada cae del 48,5 al 44\%), mientras que desde aquél momento hasta la actualidad ambas variables se disocian fuertemente: el incremento de la productividad del $32 \%$ se da en conjunción con un auténtico derrumbe del salario real del $32 \%$ (retrocediendo la participación al referido 34\%).

De esta forma, desde la perspectiva de las razones que explican la evolución de la distribución funcional del ingreso, también quedan evidenciadas las grandes diferencias existentes entre uno y otro período de la historia económica de Argentina. Ahora bien, ¿en qué medida tales procesos, en particular el ocurrido en los últimos treinta años, son propios de nuestro país? Ya observamos que, con diferencias de magnitud y variabilidad, la participación asalariada tiene una tendencia decreciente en los países bajo estudio. Pero, ¿responde a las mismas causas que en Argentina? 

internacional

\subsection{Productividad y salario argentino en perspectiva}

En los Gráficos 3 y 4 expresamos, respectivamente, la evolución de la productividad y el salario real de los países seleccionados, conjuntamente con aquellas de Argentina.

A grandes rasgos, en el primero de ellos puede verse que Estados Unidos, Francia y Japón presentan una tendencia creciente prácticamente continua de la productividad durante los sesenta años considerados (la única excepción de importancia es el estancamiento estadounidense en los ochenta). Lo mismo ocurre con Italia y España desde 1970, aunque ambos países presentan un estancamiento en los años más recientes. El menor dinamismo de la productividad en nuestro país queda claramente de manifiesto, en tanto desde los años considerados como referencia la capacidad productiva del trabajo se expandió, como mostrábamos previamente, alrededor de un 30\%, mientras que para el resto de los países la misma se incrementó entre el $75 \%$ y un $100 \%$. En este punto, debemos recordar que la referencia es exclusivamente a su evolución y no a niveles absolutos de las variables, aunque sí podemos afirmar que tal dinámica implica una ampliación de la brecha absoluta de productividad que separa a nuestro país de la correspondiente a los países seleccionados ${ }^{17}$.

En lo que respecta al salario real, en términos generales se alcanzan prácticamente las mismas conclusiones, con una excepción de importancia: en los países para los cuales contamos con información desde mediados del siglo $X X$, se observa que su ritmo de crecimiento se lentifica desde mediados de los setenta, tendencia a la que se "acoplan" Italia y España. Incluso más, esta desaceleración se transforma -en algunos momentos- en un estancamiento tal como sucede en Estados Unidos en los ochenta y en el resto de los países en los noventa. En este marco, el deterioro ya apuntado del salario real en la Argentina desde mediados de los setenta resulta mucho más llamativo y desalentador. A lo largo de estos años, mientras que en nuestro país el mismo retrocedió un $30 \%$, en

17 En un sentido, el rezago productivo se estaría produciendo inclusive si la evolución fuera idéntica ya que Estados Unidos, por ejemplo, posee una productividad mayor; por ende ante un crecimiento porcentual similar, su expansión absoluta es proporcionalmente mayor. En otros términos, si al crecer a la misma tasa la (en este caso) brecha relativa de productividad se mantiene inalterada, la distancia absoluta, por el contrario, se amplía. 
Estados Unidos se incrementó en igual proporción, mientras que en el resto de los países el crecimiento fue de algo superior al $70 \%$.

Gráfico 3: Productividad. Argentina, España, EE.UU., Francia, Italia y Japón. 1950-2008. Total de la economía. Evolución. Promedio 1970-1972 = 100

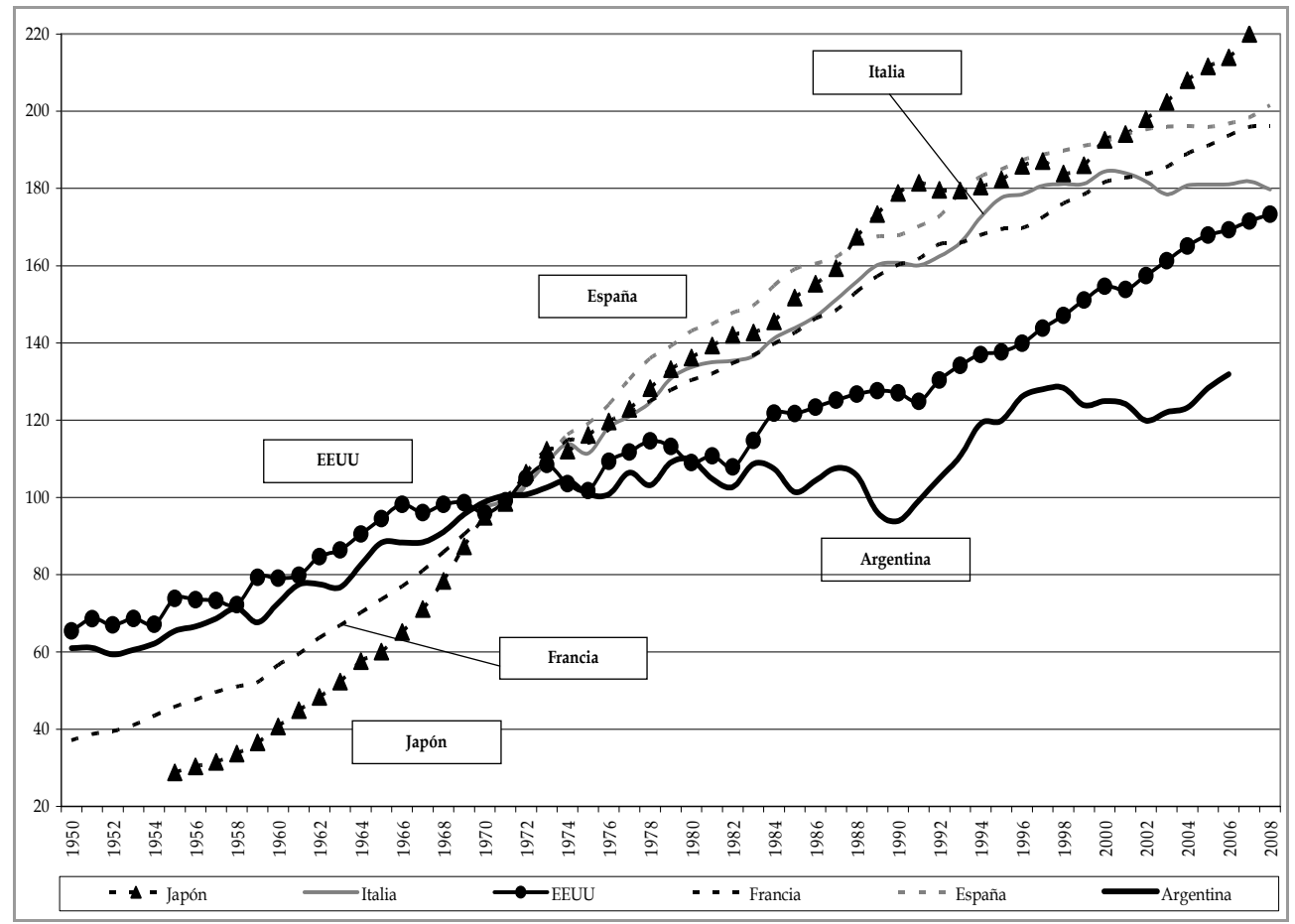

Fuente: Graña y Kennedy (2008b) y elaboración propia sobre la base de Instituto Nacional de Estadística (INE España), Bureau of Economic Analysis (BEA - EE.UU.), Institut National de la Statistique et des Études Économiques (INSEE - Francia), Istituto Nazionale di Statistica (ISTAT - Italia) y Statistics Bureau of Japan.

De esta forma, tomando en consideración las preguntas planteadas al terminar el apartado anterior, en función de lo aquí visto resulta claro que, en términos generales, el retroceso en la participación asalariada a lo largo de los últimos treinta o cuarenta años apuntado en la primera sección para los países seleccionados se explica, a diferencia de lo ocurrido en Argentina, por un incremento de la productividad mayor al incremento de la capacidad de compra del salario.

En conclusión, si al analizar los datos argentinos concluimos que en el marco del modelo denominado ISI la productividad y el salario real se comportaban tal como lo esperado en la producción capitalista (en función de lo desarrollado en el apartado 2.1), mientras que lo contrario 
sucedía en el período posterior, lo planteado en este apartado a partir de la comparación internacional no hace más que reforzar tal conclusión. Como quedó evidenciado, en los países considerados desarrollados dichas variables presentan, en términos generales, una tendencia "normal", de modo que lo hallado para Argentina no es un fenómeno del capitalismo mundial sino que le es propio, consecuencia de especificidades en el funcionamiento de su sistema económico que habrá que desentrañar ${ }^{18}$.

Gráfico 4: Salario real. Argentina, España, EE.UU., Francia, Italia y Japón. 1950-2008. Total de la economía. Evolución. Promedio 1970-1972 = 100

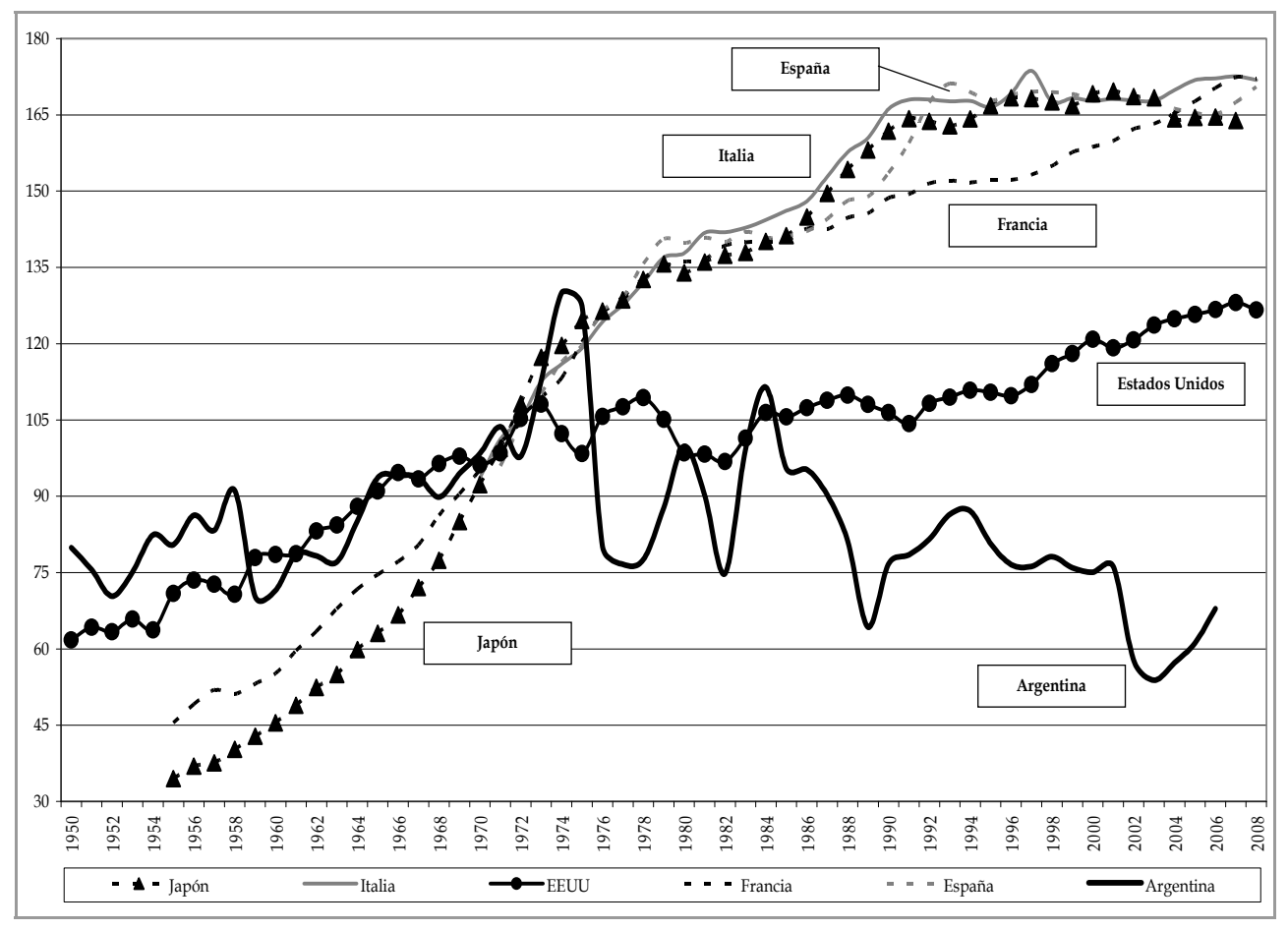

Fuente: Graña y Kennedy (2008b) y elaboración propia sobre la base de Instituto Nacional de Estadística (INE -

España), Bureau of Economic Analysis (BEA - EE.UU.), Institut National de la Statistique et des Études Économiques (INSEE - Francia), Istituto Nazionale di Statistica (ISTAT - Italia) y Statistics Bureau of Japan.

18 Con esto no estamos queriendo afirmar, obviamente, que Argentina sea el único país en tales condiciones. 


\section{LA INDUSTRIA COMO EJE DE LOS DEBATES}

Como intentamos poner de manifiesto previamente, el devenir de la economía argentina a nivel agregado en los últimos treinta años no resulta para nada alentador. Ahora bien, frente a este contexto podría decirse que el mismo es engañoso, en tanto al tratar a la economía en su conjunto se están incluyendo situaciones de las más heterogéneas; en particular, se están considerando actividades o sectores económicos que por sus características no sufren por igual los cambios en la política económica o en el contexto internacional. Es por ello que en la presente sección nos proponemos centrar la mirada en el sector tradicionalmente reconocido como el más importante de una economía: la industria. Esto es así habida cuenta tanto de los encadenamientos productivos que a partir de la misma se generan como por su capacidad de generación de empleo y desarrollo de las capacidades productivas de la fuerza de trabajo, todo lo cual Marshall (2009) agrupa bajo la denominación de "propiedades especiales"19. Para tal fin, en los Gráficos 5 y 6 expresamos, respectivamente, la evolución de la productividad y la del salario real para dicha rama de la producción ${ }^{20}$.

En relación a la productividad para el caso argentino, puede verse que la misma sigue en la industria un camino similar al de la economía agregada, aunque con tendencias más marcadas. Así, el continuo crecimiento que se verifica bajo la ISI (siempre considerando como punto de referencia el promedio 1970-1972) alcanza el 150\%, mientras que el estancamiento bajo el gobierno militar y el retroceso de los años ochenta la llevan a un nivel $30 \%$ inferior al de inicios de los setenta. A su vez, la expansión a inicios de los años noventa ronda el $125 \%$, tendencia que refuerza el argumento señalado más arriba respecto a que ese incremento se encontraba más relacionado a la eliminación de actividades que a un crecimiento genuino de la capacidad productiva del trabajo, al haber sido el sector industrial el más afectado por la apertura comercial irrestricta y

19 A su vez, la "facilidad" y abundancia de información al respecto, tanto en términos nacionales como internacionales, la constituyen en un sector apropiado para el análisis histórico y comparativo.

20 En este caso por cuestiones de espacio no trataremos específicamente la evolución de la participación asalariada porque no se diferencia sustancialmente de lo ya señalado para el total de la economía. Sólo cabe destacar que la Argentina es el único país donde la apropiación del ingreso muestra una evolución tan negativa entre 1970 y la actualidad, cayendo un $42 \%$, mientras que en los demás países muestra una estabilidad importante, con caídas que rondan entre el 3 y $5 \%$ (con excepción de Japón, que donde la participación asalariada en la industria crece un $26 \%)$. 
la apreciación de la moneda nacional. La caída en el marco de la recesión de fines de la Convertibilidad y su salida fue algo más que recuperada con el crecimiento económico de los años 2003-2006. Así, la productividad muestra hacia fines del período bajo estudio un nivel $60 \%$ más alto que el de mediados de los setenta y un $300 \%$ mayor que el de mediados de siglo pasado.

Gráfico 5: Productividad industrial. Argentina, EE.UU., Francia, Italia y Japón. 1950-2008. Evolución. Promedio 1970-1972 = 100

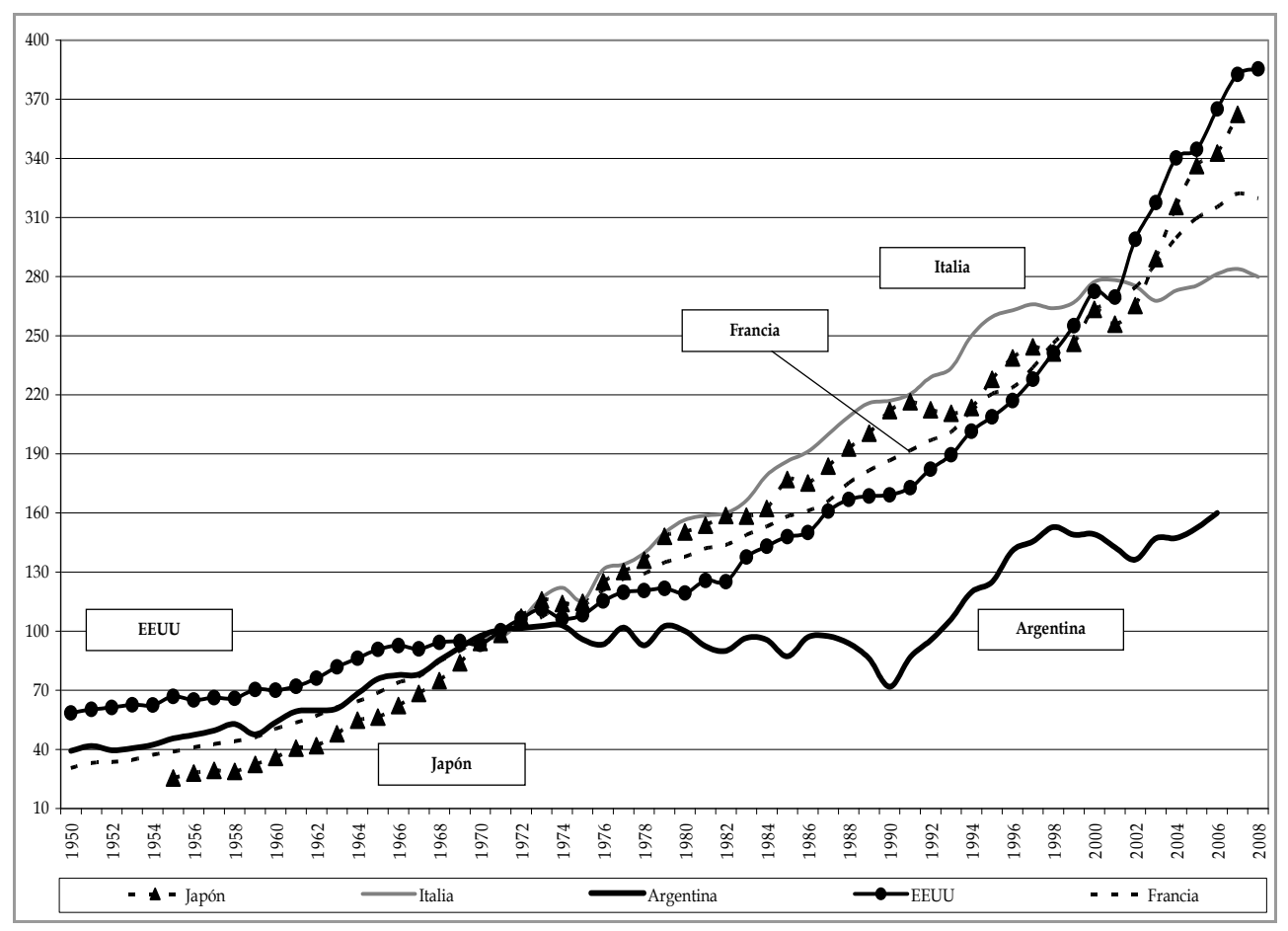

Fuente: Graña y Kennedy (2009), elaboración propia sobre la base de Bureau of Economic Analysis (BEA EE.UU.), Institut National de la Statistique et des Études Économiques (INSEE - Francia), Istituto Nazionale di Statistica (ISTAT - Italia) y Statistics Bureau of Japan.

Si la anterior descripción despierta optimismo al compararla con la evolución de la productividad de la economía agregada, esto se desvanece si se la coloca en perspectiva internacional y vemos que lo mismo ocurre en los países seleccionados. Durante la ISI la industria nacional desarrollaba la capacidad productiva del trabajo a un ritmo similar al de los países seleccionados (lo cual implica que la brecha relativa de rendimiento no se reducía), pero exactamente lo contrario sucede desde mediados de los años setenta: la productividad del trabajo industrial del 
resto de los países presenta un crecimiento prácticamente continuo en todos los años (con excepción de Italia en los años más recientes), al punto que la expansión desde mediados de los setenta hasta la actualidad va desde el 180\% (Italia) al 280\% (Estados Unidos). De esta forma, salvo lo ocurrido en los primeros años de los noventa (con las características ya mencionadas), la brecha relativa de productividad del trabajo industrial de nuestro país en relación a los países considerados no ha cesado de incrementarse.

Gráfico 6: Salario real industrial. Argentina, EE.UU., Francia, Italia y Japón. 1950-2008. Evolución. Promedio 1970-1972 $=100$

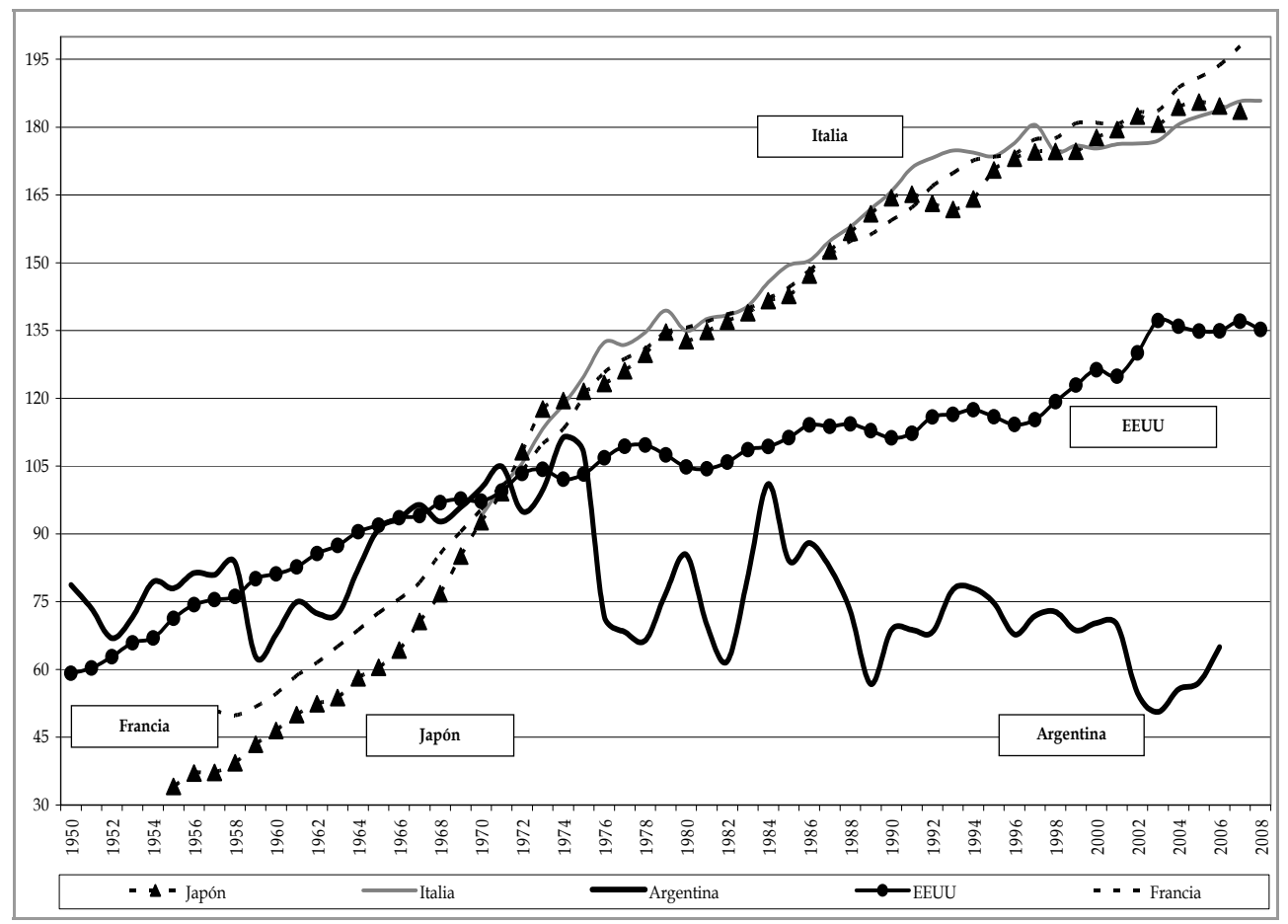

Fuente: Graña y Kennedy (2009), elaboración propia sobre la base de Bureau of Economic Analysis (BEA EE.UU.), Institut National de la Statistique et des Études Économiques (INSEE - Francia), Istituto Nazionale di Statistica (ISTAT - Italia) y Statistics Bureau of Japan.

En lo que respecta al salario real en la industria, la evolución en nuestro país es muy similar a la ya observada para el conjunto de la economía, pero siempre algo menos favorable. El resto de los países también presentan una evolución del salario real en la industria muy parecida a la del total de la economía, aunque, salvo Estados Unidos, sin los estancamientos oportunamente señalados. De esta forma, mientras que el salario real industrial argentino presenta hacia fines del período en 
cuestión un poder adquisitivo 35\% menor que el de mediados de los setenta, el de Estados Unidos se expandió en idéntica proporción, mientras que el de Francia, Italia y Japón lo hicieron en más de un $80 \%$.

En resumidas cuentas, mientras que hasta mediados de la década del setenta nuestro país expandía la capacidad productiva del trabajo y el poder adquisitivo del salario a un ritmo relativamente similar al de algunas de las economías identificadas como "avanzadas" o "desarrolladas", tanto a nivel general como en el sector industrial, a partir de allí tales tendencias se ven profundamente revertidas. Por un lado, la evolución de la productividad, positiva entre puntas pero con períodos de estancamiento e incluso retroceso, resulta marcadamente menor al de tales economías. Por el otro, el desplome del salario real contrasta abiertamente con la relativamente constante expansión de aquellos.

La pregunta principal que surge de lo anterior es, ¿qué razones pueden esgrimirse para explicar tamaña divergencia?

5. BREVE DISCUSIÓN ACERCA DE LA DESINDUSTRIALIZACIÓN COMO ÚNICA CAUSA DEL DETERIORO DE LAS CONDICIONES DE VIDA DE LA POBLACIÓN ARGENTINA

Como es de esperar, la evolución observada del salario real no puede tener las mejores consecuencias para la población argentina. La expresión más cruda de ellas la constituye, sin duda, la evolución de la proporción de hogares bajo la línea de pobreza, esto es, hogares cuyo ingreso total no alcanza para cubrir su canasta básica ni, por tanto, una reproducción normal de la fuerza de trabajo de sus habitantes. En la actualidad, el $20 \%$ de los hogares se encuentran en tal condición, proporción que cuadriplica a la vigente a mediados de los setenta ${ }^{21}$. Sin lugar a dudas, este brutal reflejo en las condiciones de vida de la población constituye el principal incentivo a investigar qué ocurrió en el funcionamiento económico de nuestro país.

21 Según la reconstrucción de la información realizada por Beccaria y Maurizio (2008) sobre la base de la Encuesta Permanente de Hogares (EPH-INDEC), los hogares bajo la línea de pobreza representaban, en 1974 , el $4 \%$ del total de hogares del país, el $6 \%$ en 1980 y $11 \%$ en 1986 , para consolidarse en torno al $15 \%$ a $20 \%$ en la década del noventa. Con la devaluación de 2002 , la misma trepó hasta el 40\%, para retornar hacia 2006 al $20 \%$. 
No procuramos aquí, por razones de espacio pero principalmente por nuestras propias limitaciones, abordar las distintas explicaciones que se ensayan para dar cuenta de lo anterior, sino simplemente poner brevemente en discusión la -quizá- más difundida: aquella que centra absolutamente su mirada en el proceso de desindustrialización sufrido por nuestro país a partir de 1976. El sentido de tal argumentación es claro y, sobre todo, plausible: si la industria tiene aquellas "propiedades especiales" referidas, una reversión del proceso de industrialización tendría un efecto sumamente negativo sobre la economía de un país.

Antes de continuar, resulta de suma importancia destacar que un proceso de desindustrialización es complejo de caracterizar. En este sentido:

Ha sido usual considerar que la caída del peso de la industria en el empleo indica que está en marcha un proceso de desindustrialización. Sin embargo, esta disminución de la participación del empleo industrial, por sí sola, no necesariamente implica desindustrialización. La pérdida de participación del empleo industrial no acompañada por la disminución del peso de la industria en la economía (producto) -o, naturalmente, por un retroceso del producto industrial- puede expresar avance tecnológico e incremento de la productividad (Marshall 2009: 3$)^{22}$.

Nuestra propuesta es, como lo hicimos en los temas tratados previamente, poner en perspectiva internacional la evolución para Argentina de los indicadores que surgen como relevantes para la identificación de un proceso de desindustrialización. Para tal fin, construimos los Gráficos 7, 8 y 9.

22 La pérdida de la proporción del empleo industrial en el total del empleo puede expresar tanto un incremento como un retroceso absoluto del empleo industrial. Por otro lado, no puede dejar de remarcarse que aquel proceso de incremento de la capacidad productiva también refiere a la tercerización (y/o deslocalización) de actividades que décadas atrás eran realizadas en la misma empresa industrial y luego han sido dejadas a empresas especializadas de otros sectores. 
Gráfico 7 (A y B): Producto a precios constantes.

Total de la economía (superior) e industria (inferior). Argentina, España, EE.UU., Francia, Italia y Japón. 1950-2006. Evolución. Promedio 1970-1972 = 100
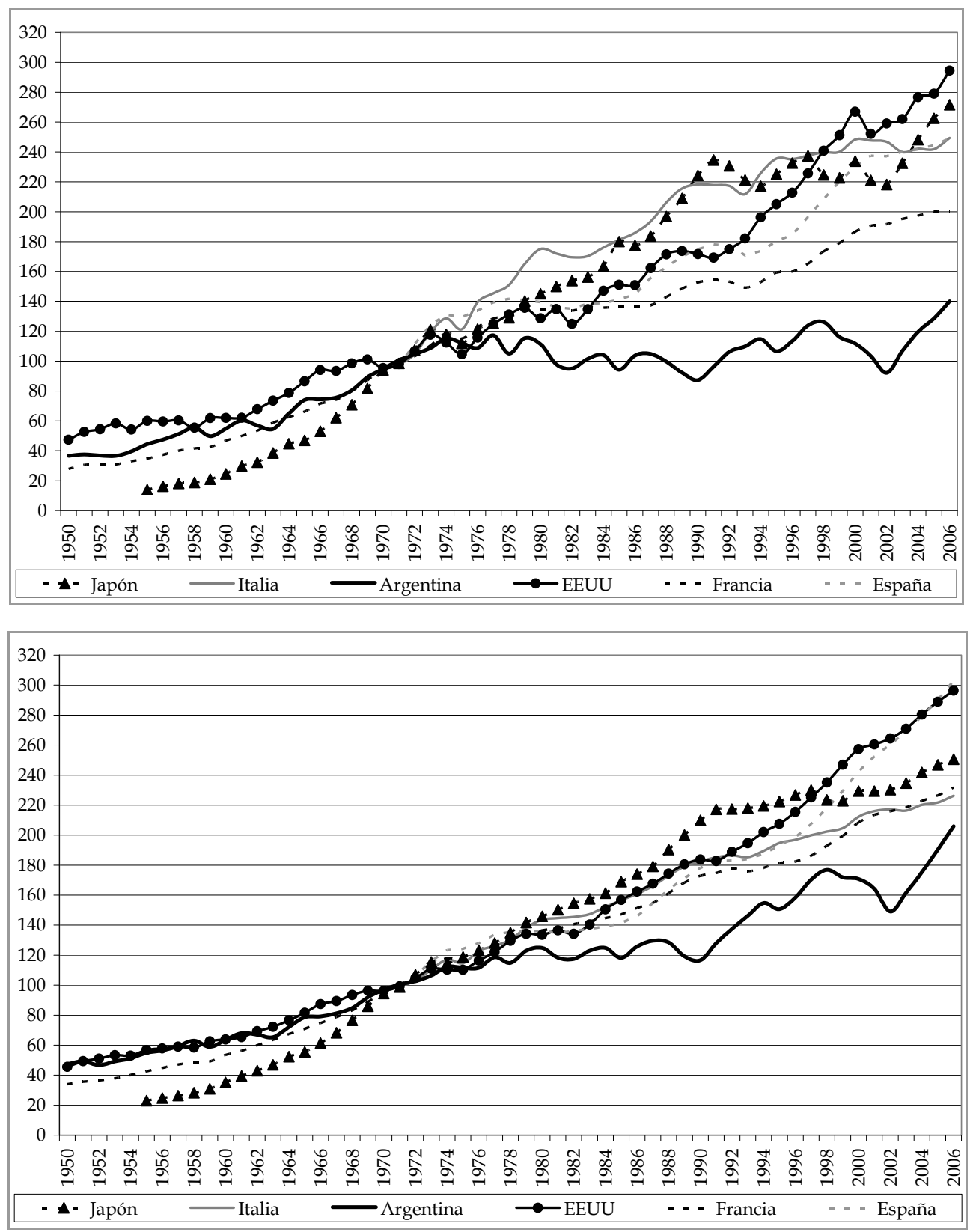

Fuente: Graña y Kennedy (2009), elaboración propia sobre la base de Bureau of Economic Analysis (BEA EE.UU.), Institut National de la Statistique et des Études Économiques (INSEE - Francia), Istituto Nazionale di Statistica (ISTAT - Italia) y Statistics Bureau of Japan. 
La información en ellos plasmada es sumamente abundante, y brinda materia prima para un análisis profundo. A nuestros fines, lo que nos interesa mostrar es que el proceso en discusión, aunque evidentemente real, tiene sus matices. En el Gráfico 7 puede verse que, en términos de la evolución de las cantidades de bienes producidos, la Argentina diverge de la correspondiente a los países seleccionados tanto para el total de la economía como para el sector industrial, con mayor intensidad en este último. De hecho, mientras que el producto a precios constantes ${ }^{23}$ del total de la economía se estanca desde mediados de los setenta hasta inicios de la Convertibilidad, el correspondiente a la industria directamente retrocede, a la vez que el repunte de los noventa es mayor para el agregado. En contraposición, el resto de los países en cuestión muestran un crecimiento del total de la economía y de la industria relativamente estable, similar para Estados Unidos, Japón y España y menor para el caso de la industria en Francia e Italia.

La evidencia previa parece ser una confirmación concluyente de la existencia de un proceso de desindustrialización en nuestro país, frente a un mundo desarrollado exento de tal problemática. Sin embargo, si observamos los Gráficos 8 y 9 dicha evidencia queda, al menos en parte, relativizada. Como podemos observar, la caída de la participación de la industria en el total de la economía a precios corrientes ${ }^{24}$ no es específica ni particularmente violenta en la Argentina ${ }^{25}$. Prácticamente lo mismo puede afirmarse en términos del peso del empleo industrial en el total del empleo: en todos los países analizados la misma retrocede casi de manera continua y similar entre sí desde los años setenta (Gráfico 9.A). Ahora bien, este retroceso relativo podría estar encerrando un incremento absoluto de la ocupación industrial, claro que inferior al crecimiento del empleo total. Sin embargo, no es esto lo que ocurre. En el Gráfico 9.B queda claro que, aunque presenta mayor variabilidad que los indicadores previos, los ocupados industriales retroceden en términos

23 Como es sabido, al valuarse las cantidades producidas en cada año a los precios de un año base (de ahí la denominación de "precios constantes"), la comparación entre distintos años del producto a precios constantes da cuenta exclusivamente de la variación de las cantidades, descontando el movimiento de precios.

24 En contraposición a lo apuntado en la nota al pie previa, la medición a precios corrientes tiene en cuenta no sólo las cantidades producidas sino también el valor unitario (en este caso, relativo) de los bienes producidos, mostrando cómo evoluciona el poder de cambiabilidad (o valor de cambio) de tales bienes.

25 En el Gráfico 8.B se refleja de modo alternativo la relación entre el producto a precios constantes de la industria y el total de la economía expresada en los Gráficos 7 (A y B). 
absolutos en todos los países, no siendo Argentina una particular excepción ni en la tendencia ni en la magnitud de la caída.

Gráfico 8 (A y B): Participación del Valor Agregado industrial en el total. Precios corrientes (superior) y constantes (inferior).

Argentina, España, EE.UU., Francia, Italia y Japón. 1950-2008. En porcentaje
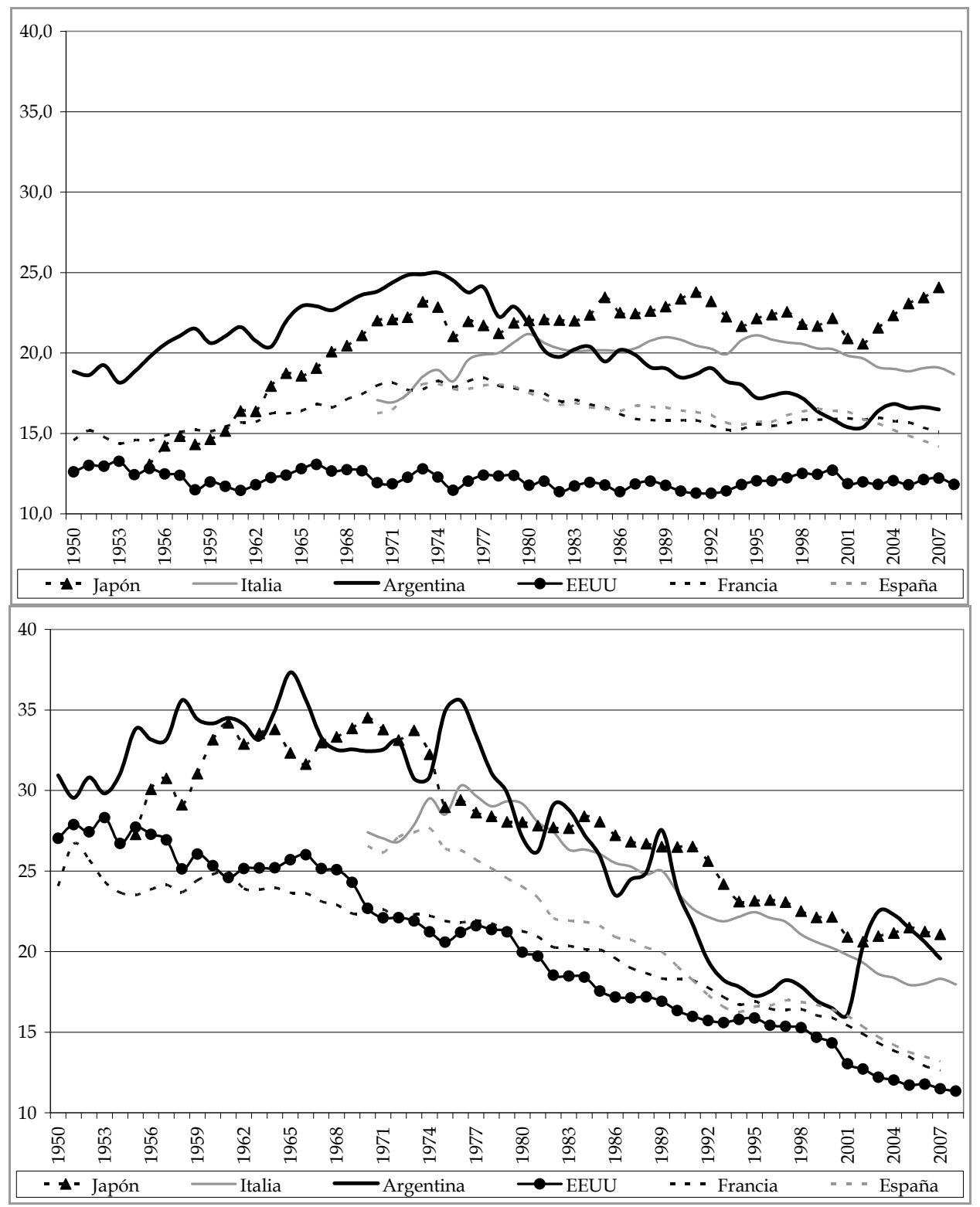

Fuente: Graña y Kennedy (2009), elaboración propia sobre la base de Bureau of Economic Analysis (BEA EE.UU.), Institut National de la Statistique et des Études Économiques (INSEE - Francia), Istituto Nazionale di Statistica (ISTAT - Italia) y Statistics Bureau of Japan. 

con débil dinámica productiva. Argentina desde mediados del siglo XX

Gráfico 9 (A y B): Participación de los empleados industriales en el empleo total.

En porcentaje (superior). Evolución de los ocupados industriales (Promedio 1970-1972=100)

(inferior). Argentina, España, EE.UU., Francia, Italia y Japón. 1950-2008
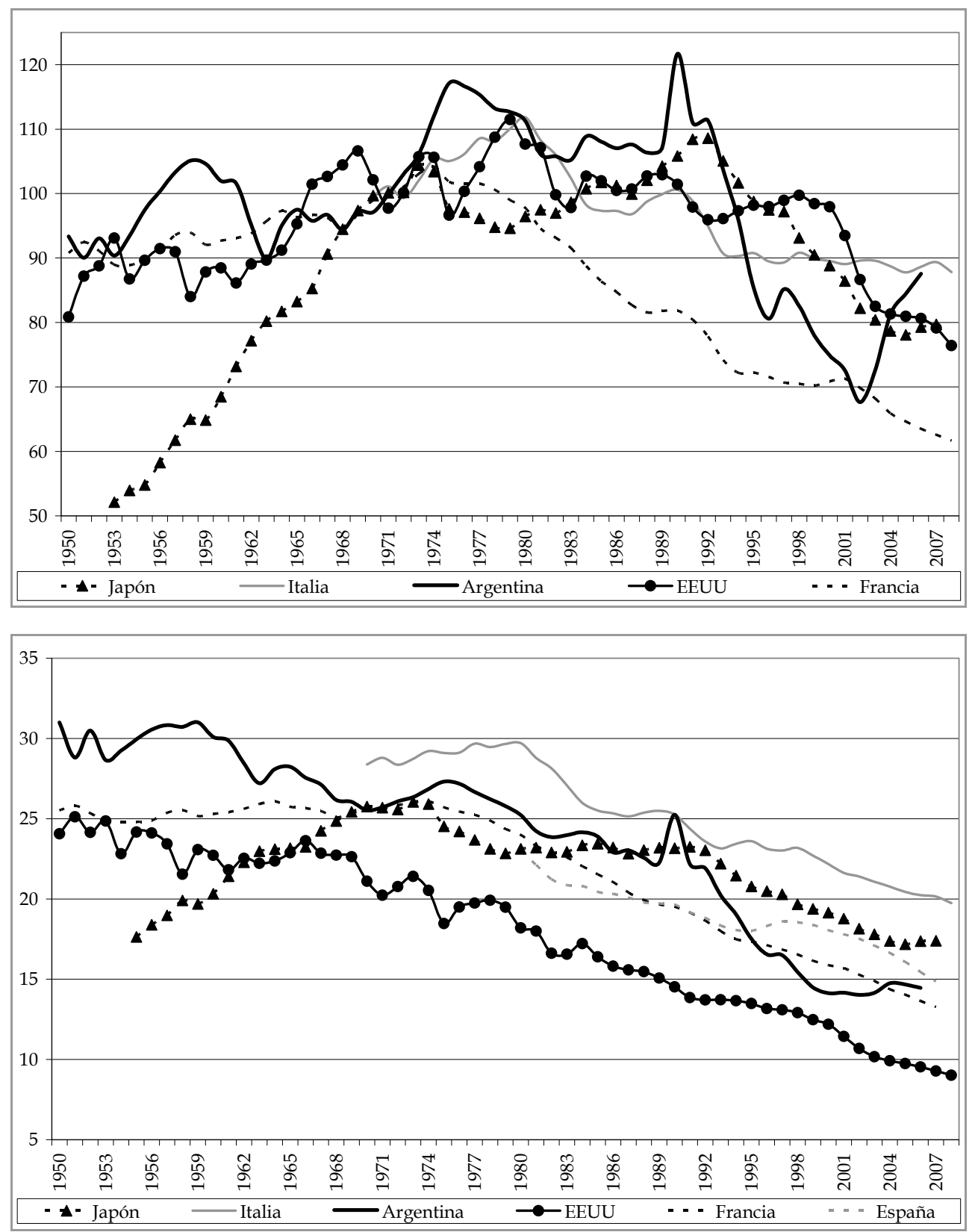

Fuente: Graña y Kennedy (2009), elaboración propia sobre la base de Bureau of Economic Analysis (BEA EE.UU.), Institut National de la Statistique et des Études Économiques (INSEE - Francia), Istituto Nazionale di Statistica (ISTAT - Italia) y Statistics Bureau of Japan. 
Con lo anterior no pretendemos afirmar, ni mucho menos, que en Argentina no se experimentó desde mediados de los años setenta un proceso de desindustrialización. El estancamiento de la producción industrial -aún mayor a la de la economía en su conjunto- en relación a los países desarrollados es una fuerte evidencia de su existencia. Sin embargo, dicha respuesta, aunque en principio verdadera, es incompleta. Es decir, no acaba de explicar las especificidades del paradigmático "caso argentino". Puestos en perspectiva internacional, el resto de los indicadores relevantes dan cuenta de que en los países desarrollados se verifican tendencias idénticas a las que al interior de Argentina se les adjudica la explicación absoluta de los males nacionales. Esto es, en esta selección de los países más avanzados del mundo, también sucede que el producto industrial retrocede en su participación en el producto total, que los ocupados industriales pierden importancia en el total de la ocupación y que, más aún, retroceden en términos absolutos.

A nuestro juicio, las explicaciones que centran su mirada exclusivamente en la desindustrialización omiten (o no otorgan gran importancia) una parte importante del problema: cuál es la capacidad productiva del trabajo de la industria argentina y, claro está, de la economía en su conjunto. Por un camino algo diferente arribamos en este apartado a un punto con el que ya nos enfrentamos en los apartados anteriores: la menor dinámica de la productividad nacional (industrial y total) en relación a los países avanzados. En la parte final del artículo procuramos presentar una aproximación inicial acerca del vínculo entre éste aspecto y el deterioro de las condiciones de vida de la población argentina, a partir de una mirada integral de los distintos resultados presentados a lo largo del trabajo.

6. A MODO DE CIERRE: UN PRIMER AVANCE SOBRE LA ESPECIFICIDAD DEL PROCESO ECONÓMICO ARGENTINO Y SUS CONSECUENCIAS SOBRE LAS CONDICIONES DE VIDA DE LA POBLACIÓN

En el segundo apartado desarrollamos el proceso de producción de plusvalía relativa en tanto forma más potente de expansión del excedente $\mathrm{y}$, por tanto, de la acumulación de capital. ¿Cómo se desarrolla dicho proceso? Esto es, ¿cómo se logra el incremento constante en la capacidad productiva del trabajo? Más allá de algunas particularidades, dichos aumentos de productividad se desarrollan a través del incremento 
de la escala de producción, resultado de la capitalización de la plusvalía. Antes que nada, ésta implica la economía de los medios de producción, la cooperación de asalariados $\mathrm{y}$, generalmente, una mayor división del trabajo. Pero su transformación fundamental reside en el reemplazo de fuerza de trabajo por maquinaria, que hace actuar a las fuerzas naturales automáticamente sobre el objeto de trabajo para transformarlo ${ }^{26}$. Por todo ello, las masas de capital puestas en producción individualmente que se requieren para mantener el ritmo de innovación son crecientes, para lo cual el primer camino es la simple capitalización del excedente obtenido (concentración del capital), pero que presenta un arma mucho más potente, rápida y efectiva para lograr el mismo objetivo: la centralización del capital en unidades privadas independientes de mayor tamaño.

De esta forma, las condiciones sociales medias de producción de cada valor de uso -que, recordemos, no surgen de un simple promedio entre los distintos capitales individuales- se encuentran en permanente transformación, tal que el precio de las mercancías ( $\mathrm{y}$, por tanto, la tasa general de ganancia) se encuentra determinado por las empresas que poseen el tamaño y formas de producción que las ponen al frente del desarrollo de las capacidades productivas del trabajo a nivel mundial. Este punto central, habitualmente olvidado en los debates económicos actuales, era reconocido por una parte también olvidada de Prebisch:

¿Hasta dónde tiende a alcanzarse esta dimensión [la óptima de tamaño o producción de los establecimientos industriales] en los países de América Latina? (...) no se ha realizado aún en estos países un estudio sistemático de la productividad y su relación con la dimensión óptima de la empresa y de la industria. Pero suelen citarse ejemplos poco halagadores, ya sea de la subdivisión de una industria en un número excesivo de empresas de escasa eficiencia dentro de un mismo país, o de la multiplicación de empresas de dimensión relativamente pequeña, en países que, uniendo sus mercados para una serie de artículos, podrían conseguir una mayor productividad. Este parcelamiento de los mercados, con la ineficiencia que entraña, constituye otro de los límites del crecimiento de la industria... (Prebisch 1986: 497).

26 No se trata, claro está, de un reemplazo absoluto, sino relativo; esto es, disminuye la proporción que representa la fuerza de trabajo con respecto al capital desembolsado. 0 , dicho en otros términos, con cada incremento de la escala se demanda proporcionalmente menos fuerza de trabajo. 
En ese movimiento, las empresas que no logran desarrollar la productividad del trabajo de modo tal de ubicarse en las condiciones medias de producción comienzan a sufrir las complicaciones que resultan de tener costos de producción más elevados $\mathrm{y}$, por tanto, obtener una tasa de ganancia inferior a la general. Ahora bien, esto no implica que las empresas menos productivas, de menor tamaño, desaparezcan automáticamente, sino que se van rezagando progresivamente al no poder hacer frente a los desembolsos de capital necesarios para mantener el ritmo de aumento de la productividad de las empresas que operan en las condiciones medias de producción:

\begin{abstract}
Cuanto mayor, relativamente, es un capital tanto mayor es la masa de plusvalía que puede obtener y tanto mayor es la posibilidad de crecimiento de este capital; tanto mayor es la escala de producción en que puede operar y tanto menor en principio es el costo de cada unidad de producto al distribuirse los costos fijos entre más unidades; tanto más convenientes y oportunas son las innovaciones técnicas que puede operar, con la consiguiente disminución en los costos unitarios, etc. (Cimillo et al. 1973: 16).
\end{abstract}

En este marco, la continuidad de empresas en tales condiciones implica que enfrentan sus mayores costos aceptando una tasa de ganancia menor a la normal (cuyo límite inferior está determinado por la tasa de interés, punto en el cual resultaría conveniente convertir la masa de capital en cuestión en capital prestado a interés $)^{27}$ o a partir de una compensación con fuentes extraordinarias de plusvalía no surgidas de su propio proceso de producción, que le permita bien la tasa de ganancia media, bien una tasa de ganancia superior a la tasa de interés.

Justamente, a lo largo del presente trabajo hemos abordado la evolución de la productividad de la economía argentina (total e industrial) en el último medio siglo en comparación a algunas de las naciones habitualmente consideradas desarrolladas, aunque no hemos trabajado lo que respecta a los valores absolutos de productividad. En otros términos, hasta aquí nada podemos decir en relación a la brecha absoluta de productividad argentina con el resto de los países en los últimos sesenta años, aunque sí estamos en condiciones de afirmar que la misma ha sufrido un importante rezago a partir de mediados de los años setenta,

27 Para un desarrollo al respecto ver Iñigo (2004). 
con particular intensidad en la industria. De esta forma, al menos desde esa época se impone una necesidad específica sobre el conjunto de la sociedad: las empresas locales deben recibir un flujo de riqueza social por fuera de sus condiciones de producción, es decir deben tener fuentes extraordinarias de plusvalía para compensar sus mayores $\operatorname{costos}^{28}$. ¿De dónde brotan dichas fuentes?

Habida cuenta de la productividad relativamente elevada que tiene el trabajo aplicado a los recursos naturales, históricamente nuestro país goza de una fuente de riqueza extraordinaria "por excelencia": la renta de la tierra portada en las mercancías agrarias. Ésta se redistribuye, por distintos mecanismos, a los distintos capitales que producen al interior del país ${ }^{29}$. Pero esto no es todo; en el proceso social que comienza con la última dictadura militar aparece una nueva fuente extraordinaria de plusvalía: el deterioro del salario real. Más específicamente, ante la inexistencia, en promedio, de rezagos significativos en cuanto a las calificaciones y aptitudes productivas de la fuerza de trabajo de Argentina respecto de los demás países, el violento deterioro del salario real ya reseñado significa el pago de la fuerza de trabajo por debajo de su valor $y$, por tanto, su constitución en una fuente extraordinaria de plusvalía que compensa la menor productividad promedio de las empresas que operan en el país ${ }^{30}$.

Así las cosas, el marcado deterioro de las condiciones de vida de la población argentina no es resultado de una fatalidad ni consecuencia de la caída del peso del producto y ocupados industriales en el total, ni de la reducción absoluta de los ocupados industriales, sino que también tiene un sentido en el marco de la forma que adopta la acumulación de capital en nuestro país. De esta forma, una tesis fundamental a seguir desarrollando es la que toma como eje central del

28 Tanto Cimillo et al. (1973) como Iñigo (2007) sostienen que la menor productividad relativa de la economía nacional también ocurre bajo la ISI. En sus argumentos (que en el caso de Iñigo se extienden hasta la actualidad) se combinan para ello, por un lado, la restringida escala del mercado interno argentino al que abastecen y, por el otro, la utilización de equipamiento industrial importado ya obsoleto en sus países de origen.

29 Para un detalle de tales mecanismos, Iñigo (2007). En otro orden, es importante destacar que durante la ISI la problemática acerca de la redistribución de los "ingresos del campo" hacia la industria era uno de los principales debates de la época, el cual más acotado en el tiempo volvió a aparecer en nuestro país a comienzos del año 2008, con el denominado "conflicto del campo".

30 Un análisis más detallado de esta cuestión puede encontrarse en Graña y Kennedy (2009). Allí estimamos que la plusvalía con fuente en el deterioro del salario real constituye entre un 15 y un $35 \%$ de la plusvalía total, según el período que se trate. 
proceso económico argentino a la potencia productiva de las empresas que producen en nuestro país.

Una nueva muestra de esto lo constituye el hecho de que a pesar de experimentar un crecimiento económico muy importante en los últimos años, nuestro país no ha logrado elevar significativamente los niveles de bienestar de la población. En ello juega un rol central la forma que toma actualmente la resolución de esa brecha de productividad: la devaluación nominal que permite encarecer las importaciones $y$, por ende, proteger a la industria nacional. Pero teniendo en cuenta que en un país que exporta mercancías agrarias que forman parte del consumo de los trabajadores eso implica un mayor precio de tales bienes (en tanto los impuestos a la exportación no neutralicen el efecto de la devaluación), aquella protección tiene como base un menor salario real ${ }^{31}$.

Ante la ausencia de una política industrial integral y coherente la productividad de las empresas argentinas continúa rezagándose. Esto implica que el salario real se ha convertido en la variable de ajuste para mantener el crecimiento económico y los puestos de trabajo. Como ha sucedido en el último tiempo, cuando el salario real tiende a recuperar su (ya históricamente degradado) nivel previo a la devaluación poniendo en peligro aquellos logros, se impulsan nuevas correcciones del tipo de cambio. Y la lógica continúa hasta la próxima vuelta. Aún más trágico es que pareciera ser que la única alternativa a ese círculo vicioso es la eliminación de empresas y el desempleo masivo de la fuerza de trabajo, tal como ocurrió en la década del noventa. Esta supuesta dicotomía nos pone frente a la necesidad de avanzar sobre el reconocimiento de las determinaciones de la acumulación de capital en Argentina, para intentar planificar una solución definitiva a los problemas históricos de nuestro país.

31 Sin embargo, es importante destacar que el valor de la fuerza de trabajo se abarata sin afectar su poder adquisitivo en la proporción de los impuestos a la exportación. A su vez, esa porción de ingresos fiscales también tienen como destino el abaratamiento de los costos de producción de las empresas y, por tanto, la compensación (en todo o en parte) de la tasa de ganancia, en tanto dichos impuestos se constituyen en la fuente de los subsidios a la producción (energía, transporte, etc.). 
BIBLIOGRAFÍA

BASUALDO, E. (2006) Estudios de historia económica argentina. Desde mediados del siglo XX a la actualidad. Buenos Aires: FLACSO / Siglo XXI editores.

BECCARIA, L. y R. MAURIZIO (2008) "Mercado de trabajo y distribución personal del ingreso". J. LINDENBOIM (comp.) Trabajo, Ingresos y Políticas en Argentina. Contribuciones para pensar el siglo XXI. Buenos Aires: EUDEBA, pp. 71-113.

Cimillo, E.; E. Lifschitz, E. Gastiazoro, H. CiafardinI y M. Turkieh (1973) Acumulación y centralización del capital en la industria argentina. Buenos Aires: Editorial Tiempo Contemporáneo.

DAMILL, M. y R. FRENKEL (1993) "Restauración democrática y política económica: Argentina, 1984-1991". J.A. MORALES y G. MCMAHON (ed.) La política económica en la transición a la democracia: lecciones de Argentina, Bolivia, Chile y Uruguay. Santiago de Chile: CIEPLAN, pp. 35-95.

FÉLIZ, M. y P. PÉREZ (2004) "Conflicto de clase, salarios y productividad. Una mirada de largo plazo para la Argentina". R. BOYER y J. NefFA (coord.) La economía argentina y sus crisis (1976-2001): visiones institucionalistas y regulacionistas. Buenos Aires: Miño y Dávila, pp. 175-219.

FERrer, A. (2004) La Economía Argentina. Desde sus orígenes hasta principios del siglo XXI. Buenos Aires: Fondo de Cultura Económica.

GonZÁLEZ, M. (2007) "Regímenes económicos y Mercado de Trabajo. Una indagación acerca de la relación entre (des)industrialización, ocupación y salarios reales", III Jornada: La política social en perspectiva histórica. Los Polvorines: Universidad Nacional de General Sarmiento.

GRAÑA, J.M. y D. KENNEDY (2008a) "Empobreciendo a los trabajadores, empobreciendo la acumulación. Producción, distribución y utilización de la riqueza social". Javier LINDENBOIM (comp.) Trabajo, ingresos y políticas en Argentina. Contribuciones para pensar el siglo XXI. Buenos Aires: EUDEBA, pp. 207-256.

- y - (2008b) Salario real, costo laboral y productividad. Argentina 19472006. Análisis de la información y metodología de estimación. Documento de Trabajo № 12. Buenos Aires: Centro de Estudios sobre Población, Empleo y Desarrollo - Instituto de Investigaciones Económicas - Facultad de Ciencias Económicas - Universidad de Buenos Aires (CEPEDIIE-FCE-UBA) diciembre. 
- y - (2009) "Salarios eran los de antes... Salario, productividad y acumulación de capital en Argentina en el último medio siglo", Revista Realidad Económica, 242, pp. 81-101.

INIIGO CARRERA, J. (2004) El capital: razón histórica, sujeto revolucionario y conciencia. Buenos Aires: Ediciones Cooperativas.

- (2007) La formación económica de la sociedad argentina. Volumen I: Renta agraria ganancia industrial y deuda externa. 1882-2004. Buenos Aires: Imago Mundi.

KENNEDY, D. y J.M. GRAÑA (2009) "Salarios y productividad en la industria argentina. Perspectivas a partir de una mirada histórica", $9^{\circ}$ Congreso de la ASET (Asociación Argentina de Especialistas en Estudios del Trabajo), Buenos Aires, agosto.

LINDENBOIM, J.; J.M. GRAÑA y D. KENNEDY (2005) Distribución funcional del ingreso en Argentina. Ayer y hoy, Documento de Trabajo $\mathrm{N}^{\circ} 4$. Buenos Aires: Centro de Estudios sobre Población, Empleo y Desarrollo Instituto de Investigaciones Económicas - Facultad de Ciencias Económicas - Universidad de Buenos Aires (CEPED-IIE-FCE-UBA), junio.

-, D. KENNEDY y J.M. GRAÑA (2010) "La relevancia del debate sobre la distribución funcional del ingreso", Revista Desarrollo Económico, 196, 49, pp. 541-571.

MARSHALL, A. (2009) "Desempeño y perfil del empleo en la industria argentina (2003-2008)", X Jornadas Argentinas de Estudios de Población, AEPA (Asociación de Estudios de Población de la Argentina), San Fernando del Valle de Catamarca, 4-6 de noviembre.

PREBISCH, R. (1986) "El desarrollo económico de América Latina y algunos de sus principales problemas", Revista Desarrollo Económico, 103, 26, pp. 479-502.

SCHVARZER, J. y A. TAVOSNASKA (2008) Modelos macroeconómicos en la Argentina: del 'stop and go' al 'go and crush', Documento de Trabajo $\mathrm{N}^{\circ}$ 15. Universidad de Buenos Aires: CESPA (Centro de Estudios de la Situación y Perspectivas de la Argentina). 